\title{
Avoidance of Host Defences by Treponema pallidum in Situ and on Extraction from Infected Rabbit Testes
}

\author{
By C. W. PENN \\ Department of Microbiology, University of Birmingham, Birmingham B15 2TT, U.K.
}

(Received 9 January 1981)

\begin{abstract}
Electron microscopic observations of acutely infected rabbit testes showed that the majority of Treponema pallidum were extracellular, and confined to interstitial regions of the tissue. Organisms were often adjacent to small blood vessels, where they should be freely accessible to non-specific humoral and cellular defence mechanisms. However, there was no accumulation of leucocytes in blood vessels or infiltration of inflammatory cells into infected areas. Inoculation of live treponemes into perforated plastic chambers which had been implanted subcutaneously in rabbits or guinea-pigs did not incite significant infiltration into the chamber fluid of inflammatory cells, in contrast to that seen after inoculation of Neisseria gonorrhoeae. Interaction of antibody from infected rabbits with live treponemes freshly extracted from rabbit testes could not be detected by an indirect fluorescent antibody method. These observations suggest that $T$. pallidum escapes recognition by host defences.
\end{abstract}

\section{INTRODUCTION}

Despite the success of penicillin in the treatment of syphilis, the disease has not been eradicated and the incidence of early syphilis is currently increasing (Report, 1980). If immunoprophylaxis is to be developed, our understanding of the pathogenicity and immunobiology of Treponema pallidum must be increased. At present it is rudimentary, due partly to our inability to culture the organism in vitro. However, some inferences about the mechanisms of pathogenesis can be made from the pathology of infection in humans or animals. Treponemes are frequently found in the intercellular matrix (Jepsen et al., 1968; Drusin et al., 1969; Hasegawa, 1969; Azar et al., 1970), but recently some intracellular organisms have been reported (Sykes \& Miller, 1971; Lauderdale \& Goldman, 1972; Sykes et al., 1974). However, the numerous free treponemes found in serum expressed from human lesions or released from infected rabbit tissues by gentle shaking suggest that an intracellular habitat is uncommon. In chancres of primary human syphilis there is no involvement of the polymorphonuclear cells of acute inflammation, but cellular infiltration of monocytes, plasma cells and lymphocytes occurs (Walter \& Israel, 1979). Thus, during the latent period between infection and development of a primary lesion, treponemal multiplication appears to occur without recognition by the host of the foreign nature of the organisms (Musher et al., 1979). Such a latent period is also seen before the development of orchitis in rabbits infected experimentally, which suggests that this may be a suitable model for the study of pathogenesis in early syphilis infection. The stimuli for acute inflammation originate from either tissue damage or activation of the complement system by either the classical or alternative pathways (Taussig, 1979). Thus, avoidance of host tissue damage, and/or non-activation of complement, appear to be significant factors in the successful invasion of host tissues by treponemes. This paper describes investigations of the habitat of the treponemes in tissues and 
the lack of stimulation of host defence mechanisms, using $T$. pallidum from testicular infection of rabbits.

\section{METHODS}

Strain of T. pallidum, storage and growth. The virulent Nichols strain was obtained from $\mathrm{Dr} \mathrm{W}$. Fowler and $\mathrm{Mr}$ D. Cox at the Special Diseases Laboratory, Royal Hospital, Wolverhampton. Suspensions in the medium of Nelson \& Diesendruck (1951) with added glycerol $(15 \%, \mathrm{v} / \mathrm{v})$ were stored in liquid nitrogen. The organisms were propagated in rabbits (Californian or New Zealand White) by intratesticular inoculation of a suspension of treponemes (about $1 \times 10^{8} \mathrm{ml}^{-1} ; 1 \mathrm{ml}$ per testis), freshly thawed or freshly obtained from another rabbit. Betamethasone (betamethasone sodium phosphate injection BP; Glaxo) was injected intramuscularly $\left(0 \cdot 1 \mathrm{mg} \mathrm{kg}{ }^{-1}\right.$ daily) to shorten the incubation period and enhance treponemal yield. In a few animals cortisone acetate (Turner \& Hollander, 1957) was used, but betamethasone appeared to cause less disturbance to water balance. Rabbits were killed within 2-3 d of palpable hardening and enlargement of the testis, and before haemorrhage commenced, i.e. 10-15 d after infection. Some animals were allowed to develop orchitis without corticosteroids, for ultrastructural comparison with those given betamethasone.

Extraction of $T$. pallidum from infected rabbit testes. Animals were killed by intravenous injection of pentobarbitone sodium. Their testes were removed, separated from adjacent tissues, halved longitudinally and the exposed internal surface was minced with fine scissors. The tissue from each testis was transferred to a $100 \mathrm{ml}$ Erlenmeyer flask with cotton-wool stopper, containing $10 \mathrm{ml}$ Hanks' balanced salt solution supplemented with $0.1 \%(\mathrm{w} / \mathrm{v})$ bovine serum albumin, $20 \mathrm{~mm}-N$-2-hydroxyethylpiperazine- $N^{\prime}$-2-ethanesulphonic acid (HEPES) and 2 mm-dithiothreitol (Norris et al., 1978), and buffered at pH 7.4. Tissues were exposed to air at all stages. The flasks were shaken on a reciprocating shaker (amplitude, $4 \mathrm{~cm}$; frequency, 2 oscillations $\mathrm{s}^{-1}$ ) in a water bath at $35^{\circ} \mathrm{C}$ for $30 \mathrm{~min}$. The suspension of treponemes was then aspirated from the tissue fragments and centrifuged at $400 \mathrm{~g}$ for $10 \mathrm{~min}$ to remove cellular debris. Immediately after harvest the treponemes were $>95 \%$ motile and they were counted by phase-contrast microscopy in a Thoma counting chamber.

Implantation, inoculation and sampling of subcutaneous chambers. Polyallomer $5 \mathrm{ml}$ centrifuge tubes (Beckman), closed at the open end with $12 \mathrm{~mm}$ suture clips, were implanted subcutaneously in anaesthetized guinea-pigs or rabbits as described by Veale et al. (1975). Six to ten weeks later the chamber fluid was sampled with a 25 -gauge needle and $1 \mathrm{ml}$ syringe, and checked for sterility and cell count. Chambers were not used if the chamber fluid contained more than $1 \times 10^{6}$ leucocytes $\mathrm{ml}^{-1}$. Chambers were inoculated by needle as above with either $1 \times 10^{8}$ freshly harvested live $T$. pallidum or $1 \times 10^{8}$ heat-killed $\left(56^{\circ} \mathrm{C}, 30 \mathrm{~min}\right.$ ) gonococci (strain BS; Veale et al., 1975) suspended in the medium used to extract $T$. pallidum. The chamber fluid was sampled at intervals and the leucocyte count was determined microscopically in a Thoma chamber. Motile and non-motile treponemes were noted but they were too sparse to count accurately. Gonococci could not be clearly differentiated from debris present in the fluid.

Indirect fluorescent antibody tests with antisera of infected rabbits. Dilutions of antisera from infected rabbits were reacted with acetone-fixed smears of treponemal suspensions obtained as described above. After washing, specific antibody was detected by addition of fluorescein isothiocyanate (FITC)-conjugated sheep anti-rabbit serum (Wellcome Reagents) and examination by fluorescence microscopy. The conjugate reacted weakly with the untreated treponemes, probably due to the presence of some rabbit immunoglobulins on the treponemal surface, but pretreatment of treponemes with normal rabbit serum did not increase the background fluorescence. While sera taken from infected rabbits at the time of maximum orchitis (10-15 d) were only weakly reactive, strong reactions (at dilutions $\geqslant 1 / 100$ ) were obtained after infection for $1-2$ months. Such antisera were used at a dilution of $1 / 20$ as follows. Freshly harvested suspensions of live $T$. pallidum $\left(1 \times 10^{8}\right.$ treponemes $\left.\mathrm{ml}^{-1} ; 1 \mathrm{ml}\right)$ were mixed with $0.05 \mathrm{ml}$ antiserum, and incubated at $37^{\circ} \mathrm{C}$ for $30 \mathrm{~min}$. Control preparations containing no antiserum or normal rabbit serum were incubated similarly. The treponemes were then deposited by centrifugation at $15000 \mathrm{~g}$ for $15 \mathrm{~min}$, and the pellets were resuspended in $10 \mathrm{ml}$ phosphate-buffered saline $\left(0.08 \mathrm{M}-\mathrm{NaCl}, 0.018 \mathrm{M}-\mathrm{KH}_{2} \mathrm{PO}_{4}\right.$, $0.057 \mathrm{M}^{-} \mathrm{Na}_{2} \mathrm{HPO}_{4} ; \mathrm{pH} \mathrm{7.2}$; PBS). After recentrifuging (15000 g, $15 \mathrm{~min}$ ) the pellets were smeared on to glass slides, dried, and fixed with cold dry acetone. Smears were covered with reagent (diluted antiserum, normal rabbit serum or buffer, followed by conjugate) and incubated at $37^{\circ} \mathrm{C}$ for $30 \mathrm{~min}$ in a moist chamber, washing between treatments for $30 \mathrm{~min}$ in PBS containing double-strength $\mathrm{NaCl}$ with agitation. After a final 30 min wash, smears were dried, mounted in glycerol buffered to $\mathrm{pH} 9.5$ and examined by fluorescence microscopy with blue light excitation (Zeiss epi-fluorescence condenser IV F1, $100 \mathrm{~W}$ tungsten-halogen illuminator).

Electron microscopy of rabbit testes. Rabbits were anaesthetized with a lethal dose of pentobarbitone $(60 \mathrm{mg}$ $\mathrm{kg}^{-1}$, intravenously), exsanguinated by cardiac puncture, and the testes were removed immediately. Small pieces were immediately excised with a scalpel and cut into approximately $1 \mathrm{~mm}$ cubes in a drop of fixative containing

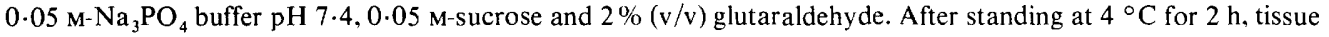
was transferred to $1 \%(\mathrm{w} / \mathrm{v})$ osmium tetroxide in the same buffer containing $0.25 \mathrm{M}$-sucrose, post-fixed for $2 \mathrm{~h}$ at room temperature, dehydrated and embedded in Araldite. Ultrathin sections were cut, stained in aqueous uranyl acetate and Reynolds' lead citrate, and examined in a Philips EM201 electron microscope. 

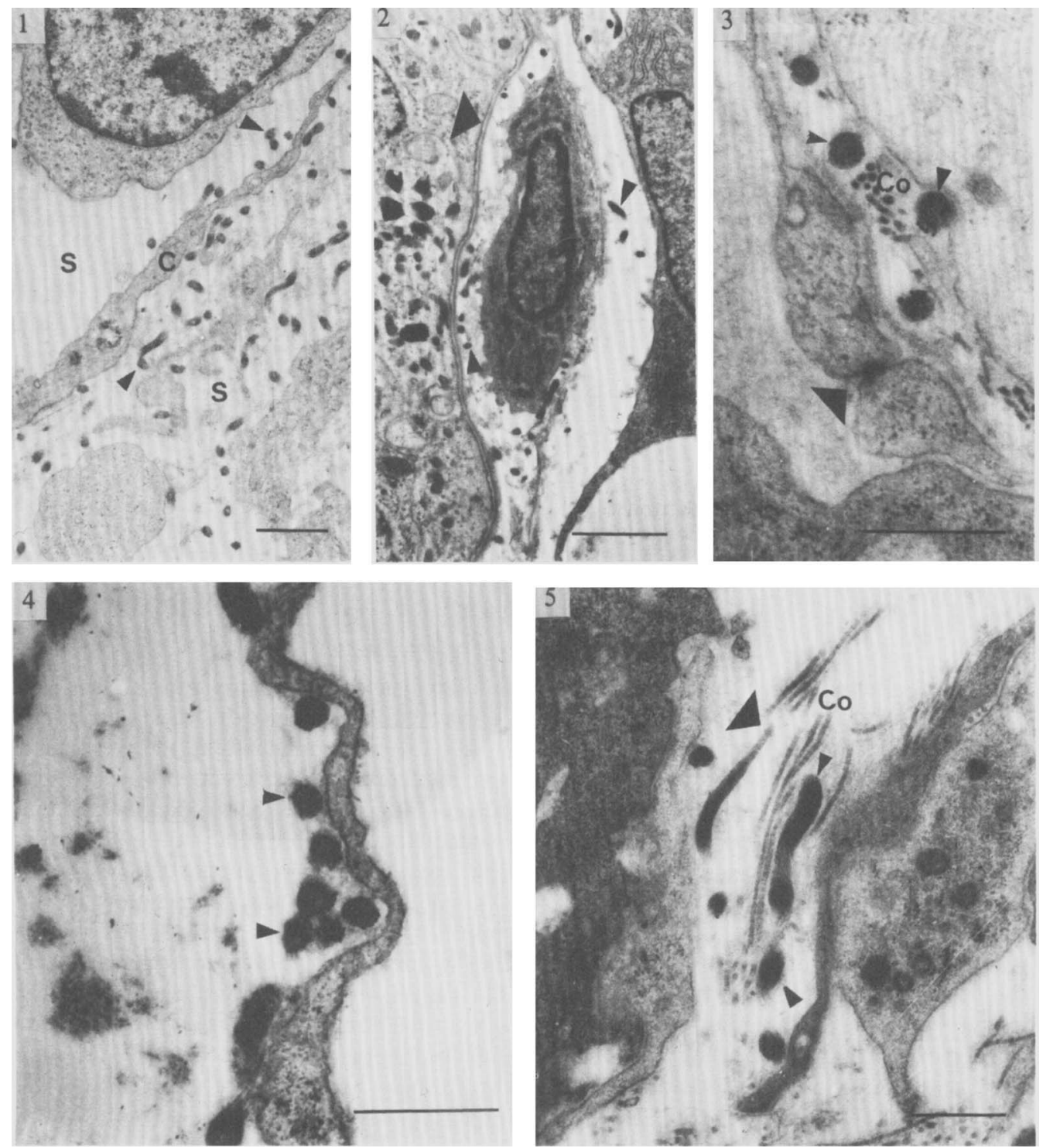

Fig. 1. Interstitial tissue from rabbit testis $15 \mathrm{~d}$ post-infection (no betamethasone). Treponemes (small arrows) are seen extracellularly in large numbers, in the wide spaces ( $\mathrm{S}$ ) between cells and cytoplasmic processes (C). The bar marker represents $1 \mu \mathrm{m}$.

Fig. 2. Rabbit testicular tissue $11 \mathrm{~d}$ post-infection (betamethasone-treated). Part of a seminiferous tubule is seen on the left, separated by the basement membrane (large arrow) from the interstitial area. Treponemes (small arrows) are seen only in interstitial areas, and large intercellular spaces are similarly limited to interstitial tissue and not seen within seminiferous tubules. The bar marker represents $2 \mu \mathrm{m}$.

Fig. 3 Part of a small blood vessel in rabbit testicular interstitial tissue $15 \mathrm{~d}$ post-infection (no betamethasone). Treponemes (small arrows) are seen among collagen fibres $(\mathrm{Co})$ in the sub-endothelial space, close to a junction complex between two endothelial cells (large arrow). The bar marker represents $0.5 \mu \mathrm{m}$.

Fig. 4. Interstitial tissue from rabbit testis $15 \mathrm{~d}$ post-infection (no betamethasone). Treponemes (small arrows) are closely apposed laterally to a cellular process. The bar marker represents $0.5 \mu \mathrm{m}$.

Fig. 5. Interstitial tissue from rabbit testis $11 \mathrm{~d}$ post-infection (betamethasone-treated). A tip organelle (large arrow) is seen in longitudinal section and appears to be unattached to any host cell. The treponemes (small arrows) are among collagen fibres (Co). The bar marker represents $0.5 \mu \mathrm{m}$. 


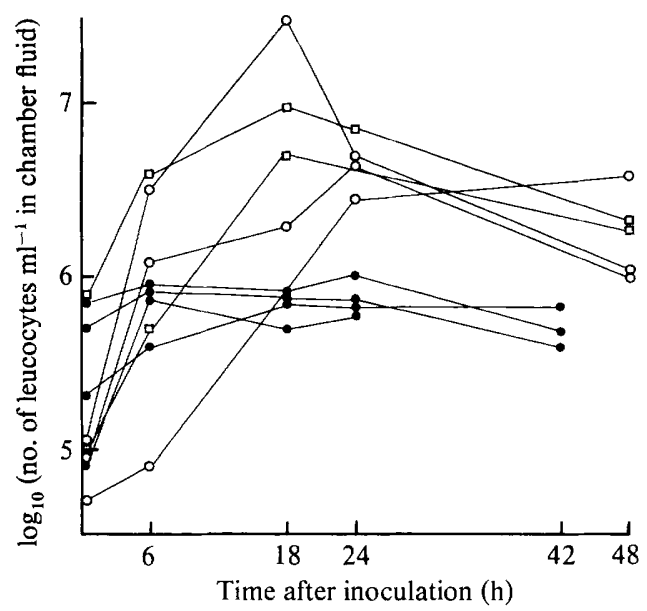

Fig. 6. Leucocyte counts in subcutaneous chambers in rabbits after inoculation of live T. pallidum (○), heat-killed gonococci $(O)$ or both together $(\square)$. Each curve represents the results from one chamber. Mean counts are not given because pre-infection counts were not all identical.

\section{RESULTS}

\section{Electron microscopy of infected testes}

Infected tissues from seven betamethasone-treated and five untreated rabbits were examined and all appeared similar. Treponemes were easily identified by their osmiophilic nature and characteristic shape. In tissues taken 10-15 d after inoculation, the treponemes were extracellular and often grouped in considerable numbers (Fig. 1). Infection was limited to interstitial regions; the seminiferous tubules adjacent to infected areas did not contain treponemes (Fig. 2). Distension of tissue by oedematous fluid, leading to formation of extensive cellular processes and large intercellular spaces, was also confined to interstitial regions. Treponemes were often seen near small blood vessels, sometimes in the sub-endothelial space (Fig. 3), yet increased numbers or margination of leucocytes in these blood vessels was not apparent, and in fact acute inflammatory (polymorphonuclear) cells were rarely seen even in heavily infected areas. The degree of association of treponemes with host cells could only be assessed subjectively, due to the contorted shape of the organisms which dictated that only a small part could be observed in any one thin section. While some treponemes were closely apposed to host cells (Fig. 4), many appeared freely suspended in the intercellular fluid or matrix, as in Fig. 1. Occasionally treponeme tip organelles were seen; in general these did not appear to be attached to host cell membranes (Fig. 5). Treponemes were frequently associated with collagen fibres (Fig. 5). No evidence of a treponemal outer membrane external to the periplasmic fibrils was seen.

\section{Leucocyte migration into subcutaneous chambers}

The leucocyte count in chamber fluid of rabbits or guinea-pigs was normally less than $1 \times$ $10^{6} \mathrm{ml}^{-1}$ before chambers were infected. After inoculation of $1 \times 10^{8}$ treponemes per chamber (to give about $2.5 \times 10^{7} \mathrm{~m}^{-1}$ in chamber fluid), leucocyte counts increased but rarely exceeded $1 \times 10^{6} \mathrm{ml}^{-1}$, whereas after inoculation of similar numbers of gonococci, counts rose to between $5 \times 10^{6} \mathrm{ml}^{-1}$ and $5 \times 10^{7} \mathrm{ml}^{-1}$. When treponemes and gonococci were inoculated simultaneously, a cellular response similar to that seen with gonococci alone occurred. Results obtained in rabbits are shown in Fig. 6, and were similar to those obtained with a similar number of chambers in guinea-pigs. In rabbits, treponemes were visible in chamber fluid for up to $24 \mathrm{~h}$ post-inoculation, but had all lost motility by $6 \mathrm{~h}$, whereas in guinea-pig chamber fluid motile treponemes were visible for up to $72 \mathrm{~h}$. 


\section{Reaction of antibody with freshly harvested treponemes}

When suspensions of freshly harvested treponemes were incubated with antiserum from infected rabbits they did not react with antibody since after fixation and treatment with buffer or normal rabbit serum followed by fluorescein-conjugated anti-rabbit antibody, the organisms were not stained. In contrast, when acetone-fixed smears of the same treponemal suspensions were incubated with rabbit antiserum and then treated with the fluoresceinconjugated anti-rabbit antibody, all the treponemes were brightly fluorescent.

\section{DISCUSSION}

The most striking observation by electron microscopy of rabbit testes $10-15 \mathrm{~d}$ after infection was the extracellular location of the vast majority of treponemes, which is counter to the suggestion (Turk, 1979) that an intracellular location protects the organisms from host defences. While this may be true to some extent in later stages of the disease (some intracellular treponemes were seen in tissues taken from rabbits 1-2 months after infection), it appears that an intracellular habitat is not significant in the pathogenesis of primary syphilitic lesions, at least in the rabbit. Hence, in these early stages the organism seems able to resist humoral defences and avoid phagocytosis.

The confinement of treponemes to the interstitial tissue has also been reported by Lukehart et al. (1980) and the accumulation of treponemes near small blood vessels by Jepsen et al. (1968) and Azar et al. (1970). The latter is significant for two reasons. Firstly, proximity to blood vessels may enhance oxygen availability, which would satisfy the recently described microaerophilic requirements of this organism (Cox \& Barber, 1974; Baseman et al., 1976; Fitzgerald et al., 1977). Secondly, it is evident that the organisms are resistant to non-specific and immunospecific humoral defences during this stage of the infection. Host plasma proteins including natural or specific antibody and complement will be abundant near the blood vessels, since their escape is indicated by the extensive oedema in testicular lesions. The exclusion of infection from the seminiferous tubules argues against the hypothesis that multiplication may take place in immunologically privileged tissues distal to the blood-testis barrier.

Close lateral association of treponemes with cells was sometimes seen (Fig. 4), and this may relate to the tendency for treponemes to stick to tissue culture cells (Fitzgerald et al., 1977; Hayes et al., 1977) or macrophages (Brause \& Roberts, 1978). However, many treponemes were apparently freely suspended in intercellular spaces which presumably contained oedema fluid, and thus universal association of treponemes with host cells did not occur.

The existence of an outer envelope external to the cell wall and periplasmic fibrils of $T$. pallidum has long been postulated (Christiansen, 1963), and more recent observations on treponemes in infected testes indicated an outer membrane covering the periplasmic fibrils (Johnson et al., 1973). The apparent absence of such an outer membrane in the preparation described here raises doubts about its existence which have been expressed previously (Sykes \& Miller, 1973) following examination of organisms extracted from tissue. Holt (1978) suggested that differences may have been due to differences in procedure, but the fixation of tissue described here was essentially similar to that used by Johnson et al. (1973), and the possibility of differences between strains used in different laboratories cannot be excluded.

Few polymorphonuclear cells were seen in the acute testicular lesions and live treponemes did not attract leucocytes into chambers implanted subcutaneously into rabbits or guinea-pigs. The cellular inflammatory response to gonococci, a typical pyogenic organism, was not reduced in the presence of treponemes. This suggested that the treponemes did not actively suppress inflammation but failed to incite it when injected without gonococci. Treponemes quickly lost motility and presumably viability in rabbit chambers, but not in guinea-pig chambers (this reflects the fate of gonococci in chambers in rabbits and guinea-pigs: Veale et 
al., 1975). The nature of the bactericidal factors in rabbit chamber fluid is not known, but the environment there must differ from that in the interstitial fluid of rabbit testes in which the treponemes survive and multiply.

Lack of antibody binding to unfixed treponemes may be due to the presence of a non-antigenic barrier surrounding the treponemes. Alderete \& Baseman (1979) reported that host proteins including immunoglobulins were bound to the surface of $T$. pallidum freshly harvested from rabbit testes, and suggested that their acquisition constituted an immunological disguise by the organisms. Indeed, the weak reaction of untreated (i.e. no added specific antibody) treponemes with the fluorescein-labelled anti-rabbit immunoglobulin suggested the presence of some host immunoglobulin. Whether the host proteins are sufficient to prevent recognition of organisms as foreign, or whether other, more antigenically active pathogenic bacterial species grown in vivo acquire comparable amounts of host proteins, has not yet been shown.

Taken together, these observations suggest a mechanism for the pathogenesis of early syphilis infection. It appears that in vivo the treponemes are not recognized as foreign antigens by host antibody, which in the early phases of infection would be natural, cross-reacting antibody. In the absence of antibody combination, complement would not be fixed and leucocyte chemotactic factors would not be generated. This would result in the observed lack of acute inflammation. Lack of production of toxic products and toxic cell damage might also contribute to the absence of host reactions during early infection. The eventual appearance of lesions may result from breakdown of organisms after their initial undetected growth during the latent period. Toxic and antigenically active products would be released and the host immune system stimulated.

The surface structure of $T$. pallidum which masks the organisms from host defence mechanisms will be investigated.

Thanks are due to Miss E. Walker, Mr J. Rhodes, Mrs J. Lichfield and Mr D. Ruffles for excellent technical assistance, and to the Wellcome Trust for financial support.

\section{REFERENCES}

Alderete, J. F. \& Baseman, J. B. (1979). Surface-associated host proteins on virulent Treponema pallidum. Infection and Immunity 26, 1048-1056.

Azar, H. A., Pham, T. D. \& Kurban, A. K. (1970). An electron microscopic study of a syphilitic chancre. Archives of Pathology 90, 143-150.

Baseman, J. B., Nichols, J. C. \& HaYes, N. S. (1976). Virulent Treponema pallidum: aerobe or anaerobe? Infection and Immunity 13, 704-711.

Brause, B. D. \& RoberTs, R. B. (1978). Attachment of virulent Treponema pallidum to human mononuclear phagocytes. British Journal of Venereal Diseases 54, 218-224.

Christiansen, S. (1963). Protective layer covering pathogenic Treponemata. Lancet 1, 423-425.

Cox, C. D. \& BARBER, M. K. (1974). Oxygen uptake by Treponema pallidum. Infection and Immunity 10 , 123-127.

Drusin, L. M., Roulller, G. C. \& Chapman, G. B. (1969). Electron microscopy of Treponema pallidum occurring in a human primary lesion. Journal of Bacteriology 97, 951-955.

Fitzgerald, T. J., Johnson, R. C., Sykes, J. A. \& Miller, J. N. (1977). Interaction of Treponema pallidum (Nichols strain) with cultured mammalian cells: effects of oxygen, reducing agents, serum supplements and different cell types. Infection and Immunity 15, 444-452.

Hasegawa, T. (1969). Electron microscopic observations on the lesions of condyloma latum. British Journal of Dermatology 81, 367-374.

Hayes, N. J., Muse, K. E., Collier, A. M. \& Baseman, J. B. (1977). Parasitism by virulent Treponema pallidum of host cell surfaces. Infection and Immunity 17, 174-186.

HoLT, S. C. (1978). Anatomy and chemistry of spirochaetes. Microbiological Reviews 42, 114-160.

JEPSEN, O. B., Hovind-Hougen, K. \& Birch-Andersen, A. (1968). Electron microscopy of Treponema pallidum Nichols. Acta pathologica et microbiologica scandinavica 74, 241-258.

Johnson, R. C., Ritzi, D. \& Livermore, B. (1973). Outer envelope of virulent Treponema pallidum. Infection and Immunity 8, 291-295.

Lauderdale, V. \& Goldman, J. N. (1972). Serial ultrathin sectioning demonstrating the intracellularity of Treponema pallidum. British Journal of Venereal Diseases 48, 87-96.

Lukehart, S. A., Baker-Zander, S. A., Lloyd, R. M. C. \& SELL, S. (1980). Characterization of lymphocyte responsiveness in early experimental syphilis. II. Nature of cellular infiltration and 
Treponema pallidum distribution in testicular lesions. Journal of Immunology 124, 461-467.

Musher, D. M., Baughn, R. E. \& Knox, J. M. (1979). Infection due to Treponema pallidum escape from immune surveillance. In Immune Mechanisms and Disease, pp. 341-352. Edited by D. B. Amos, R. S. Schwartz \& B. W. Janicki. New York: Academic Press.

Nelson, R. A. \& Diesendruck, J. A. (1951). Studies on treponemal immobilising antibodies in syphilis. Journal of Immunology 66, 667-685.

Norris, S. J., Miller, J. N., Sykes, J. A. \& Fitzgerald, T. J. (1978). Influence of oxygen tension, sulfhydryl compounds and serum on the motility and virulence of Treponema pallidum (Nichols strain) in a cell free system. Infection and Immunity 22, 689-697.

REPORT (1980). Sexually transmitted diseases. Extract from the Annual Report of the Chief Medical Officer of the Department of Health and Social Security for the Year 1978. British Journal of Venereal Diseases 56, 178-181.

Sykes, J. A. \& Miller, J. N. (1971). Intracellular location of Treponema pallidum (Nichols strain) in the rabbit testis. Infection and Immunity 4, 307-314.

Sykes, J. A. \& MilleR, J. N. (1973). Ultrastructural studies of treponemes: location of axial filaments and some dimensions of Treponema pallidum (Nichols strain). Treponema denticola and Treponema reiteri. Infection and Immunity 7, 100-110.

Sykes, J. A., Miller, J. N. \& Kalan, A. J. (1974). Treponema pallidum within cells of a primary chancre from a human female. British Journal of Venereal Diseases 50, 40-44.

Taussig, M. J. (1979). Processes in Pathology. Oxford: Blackwell Scientific Publications.

TURK, J. L. (1979). Immunology of chronic infections. In Immunological A spects of Infectious Disease, pp. 421-460. Edited by G. Dick. Lancaster: MTP Press.

Turner, T. B. \& Hollander, D. H. (1957). Biology of the treponematoses. W.H.O. Monograph Series, No. 37. Geneva: W.H.O

Veale, D. R., Smith, H., Witt, K. A. \& Marshall, R. B. (1975). Differential ability of colonial types of Neisseria gonorrhoeae to produce infection and an inflammatory response in subcutaneous perforated plastic chambers in guinea-pigs and rabbits. Journal of Medical Microbiology 8, 325-335.

WALter, J. B. \& IsRael, M. S. (1979). General Pathology, 5th edn. Edinburgh: Churchill Livingstone. 